\title{
EL TURISMO RURAL: UNA ALTERNATIVA PARA EL DESARROLLO INTEGRADO DE LOS MUNICIPIOS RURALES DE LA MONTAÑA ALICANTINA
}

\author{
Matarredona Coll, Enrique ${ }^{1}$ \\ Ivars Baidal, Josep ${ }^{2}$
}

\section{RESUMEN}

En este artículo planteamos un modelo de desarrollo que, como objetivo global, pretende promover el crecimiento y frenar la regresión demográfica de La Montaña, al objeto de romper su aislamiento, mejorar la calidad de vida de sus habitantes, mejorar los recursos económicos disponibles y proteger el patrimonio natural y cultural. La estrategia de un desarrollo turístico en espacio rural puede ser la alternativa aconsejable para incrementar la rentabilidad de estas áreas del interior montañoso alicantino, en el bien entendido que se trata de potenciar un turismo integrado con las restantes actividades económicas, con el medio ambiente, con el patrimonio cultural y con la población autóctona.

Palabras clave: áreas de montaña, desarrollo integrado, turismo rural, regresión demográfica.

\section{ABSTRACT}

In this study we explain a model of development which tries to promote the growth and restrain the demographic decrease in «La Montaña», as a global

1 Instituto Universitario de Geografía. Universidad de Alicante.

2 Geógrafo, realiza la Memoria de Licenciatura «El potencial desarrollo turístico de la montaña alicantina», para lo cual ha disfrutado de una beca de investigación de la Fundación Cavanilles de Altos Estudios Turísticos. 
objetive, for braking its isolation, improving the quality of its inhabitants life, increasing the economical resorts and protecting the natural and cultural heritage. The strategy of a turistic development in a rural place could be the best option for the increment of its own profitability all around the interior mountains in Alicante, that is understood that the intention is to promote a kind of tourism integrated into the rest of the economical activities, the environment, the cultural heritage and with the autochtonous population.

Key words: Areas of mountain, integrated development, rural tourism, demographic decrease.

\section{Delimitación espacial de la montaña alicantina}

El área de estudio del presente trabajo de investigación se localiza, conforme puede observarse en los mapas correspondientes (topográfico y división municipal), en la parte nordoriental de la provincia de Alicante; zona de influencia de las Sierras de Benicadell, Mariola, Aixortá, Serrella y Aitana, entre otras; alineaciones prebéticas, de elevadas cotas, que determinan los fuertes desniveles capaces de reforzar la percepción del área como montañosa. Todas ellas superan los $1.000 \mathrm{~m}$ de altitud y a escasa distancia del litoral, por ello no es de extrañar que se haya intentado generalizar ese híbrido nombre de «La Montaña» para esta región, en la que participan hasta cuatro comarcas alicantinas (l'Alcoià, la Marina Baja, la Marina Alta y l'Alacantí).

En concreto, el área de trabajo queda delimitada física y perceptivamente por una serie de hitos geográficos: al este, la turgente Sierra de Ferrer, el valle de Jalón y el área deprimida de la marjal de Pego (al NE); el enhiesto y apitonado Puig Campana y el conjunto del Cabeçó d'Or en el límite meridional; a poniente, la Sierra de Plans y su continuación por la Sierra de Mariola, ajustada al lado occidental de la fosa tectónica alcoyana; y finalmente, el conjunto de Benicadell y de la Sierra del Almirante, que marcan el cierre del sector, a septentrión.

Se trata de un espacio en el que, si el carácter montano del paisaje resulta evidente, el grado de desarrollo socioeconómico no lo es tanto. En efecto, en un primer nivel de análisis, a escala comarcal, la tasa de despoblación no es significativa, incluso se ha experimentado un cierto crecimiento; ha habido también un incremento de las actividades industriales y terciarias en conexión con un sistema de ciudades relativamente homogéneo: Alcoy, Cocentaina, Muro, Ibi, Pego, Benidorm, son núcleos urbanos importantes, enclavados en la zona o en su proximidad más inmediata.

En otro orden de observación - a escala municipal— la situación no es tan homogénea ni favorable: los pequeños municipios de la Vall de Planes, Vall de Gallinera, Vall de Seta, Vall de Ebo, Vall de Perpuxent, han sufrido fuertes 


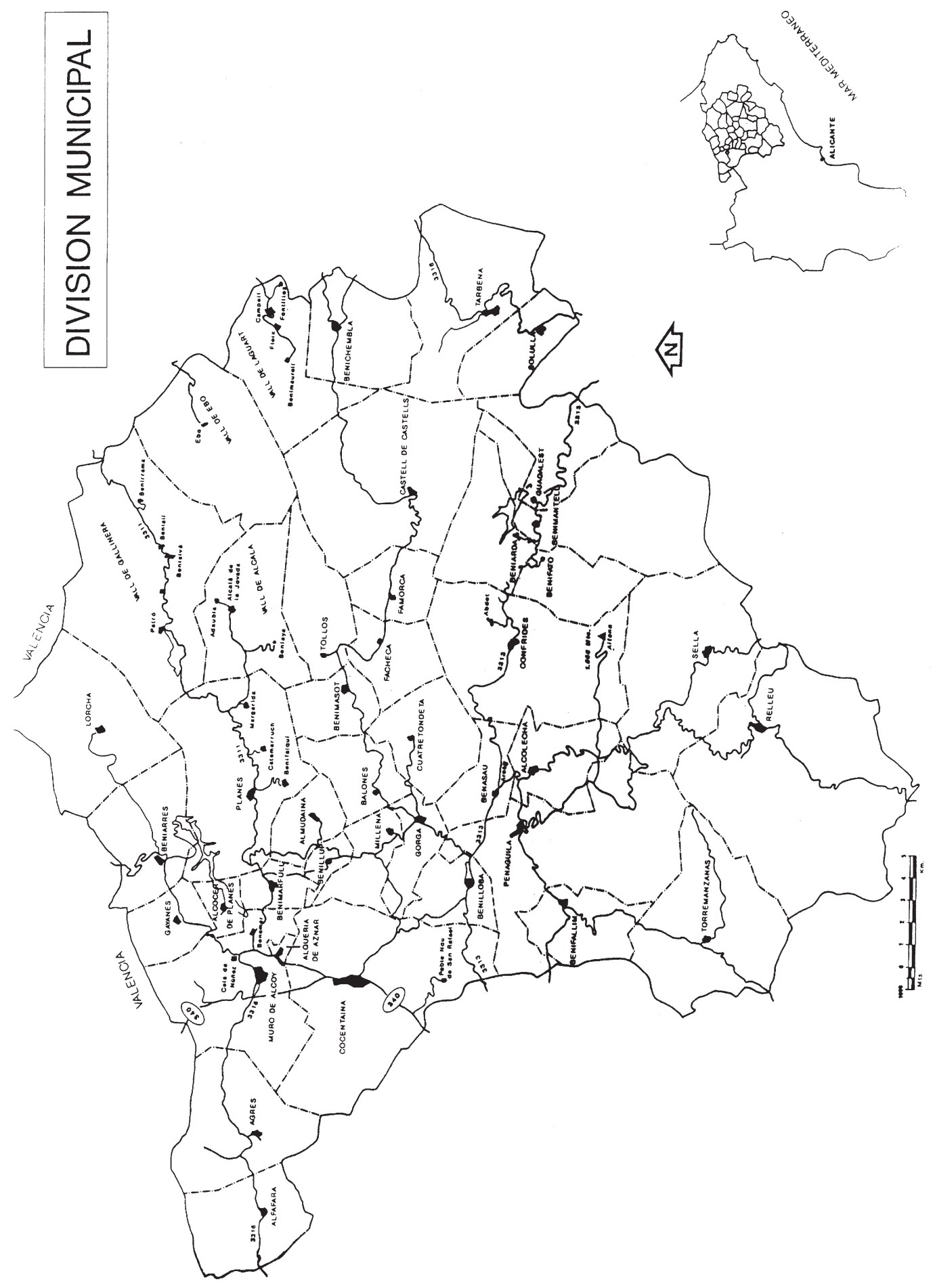




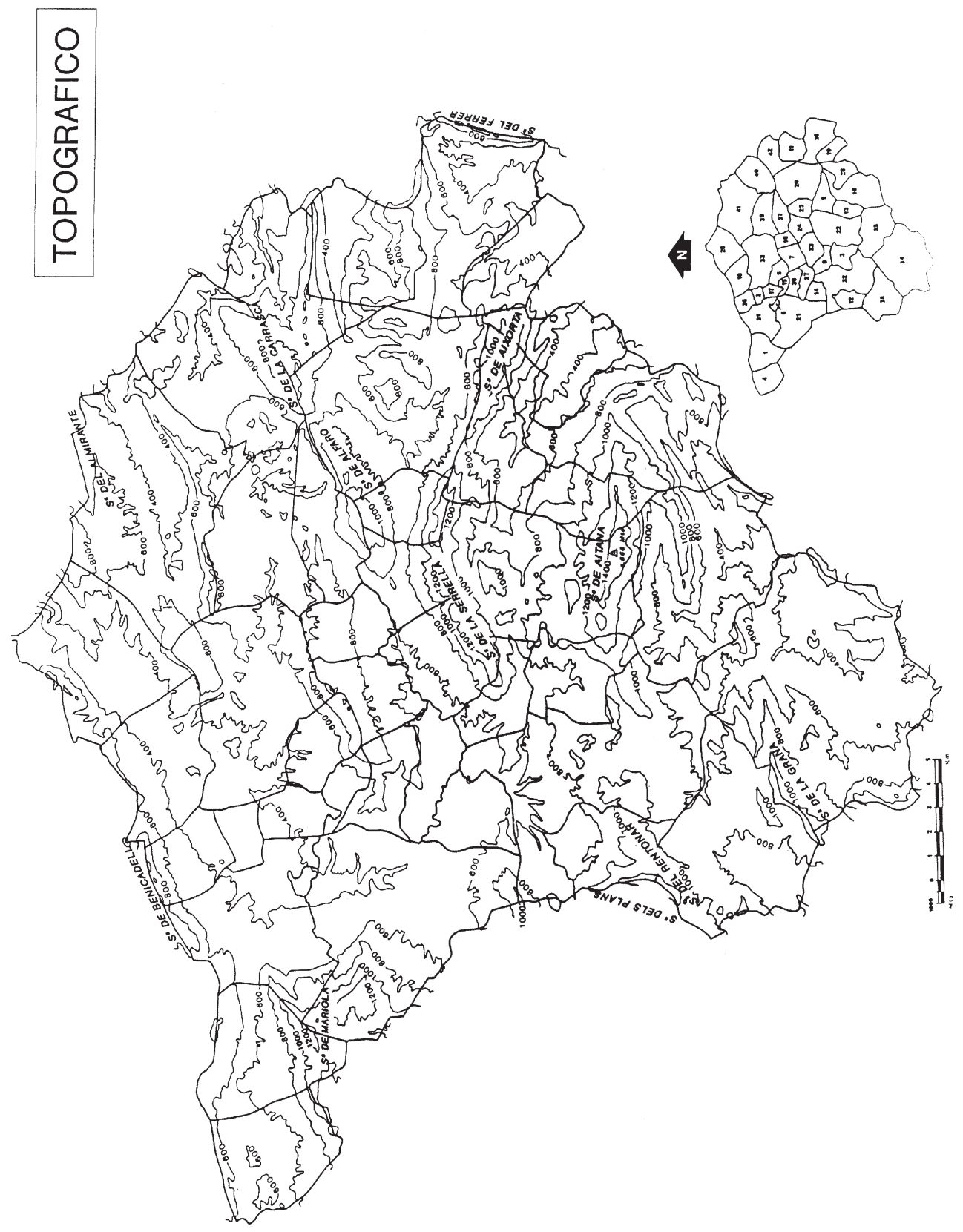

drenajes de población, con el abandono subsiguiente de algunos núcleos. En este caso se puede hablar de una situación de depresión localizada en ciertos municipios caracterizados por sus reducidas dimensiones, ubicación montañosa y alejamiento de los principales centros comarcales. 


\section{La actividad turística en el marco de un desarrollo rural integrado}

Esta compleja problemática justifica la reflexión sobre dicha zona con el fin de reactivarla y evitar el incremento del desequilibrio territorial, entendido como expresión y consecuencia de las contradicciones del desarrollo convencional, en un espacio en el que se ha ejercido un notable drenaje de mano de obra y una nula inversión en infraestructuras. El resultado final consiste en la incapacidad de este área para alcanzar el «standard» medio en la evolución socioeconómica, la cual, indefectiblemente, nos lleva a postular un modelo de desarrollo aplicable a estos espacios montanos alicantinos, modelo que pasa por un desarrollo integrado (FRUTOS, 1985).

El objetivo final del desarrollo integrado es llegar a conseguir que este área de montaña se estructure como territorio activo y no «como espacio pasivo» que acoge funciones dependientes de «centros» más o menos alejados. Dicho desarrollo supone costes adicionales impuestos, tanto por las condiciones restrictivas del medio físico como por el abandono en que se han mantenido en los últimos años (CRUZ, 1988).

Por lo tanto, se hace necesario partir del convencimiento de que existe una responsabilidad social en la reactivación y desarrollo de La Montaña, superando una posible contradicción: la de instaurar un «paraguas» protector para esta zona que promueva un desarrollo en «invernadero», aislado por completo del mercado. No es deseable una protección basada en el aporte continuo de recursos por parte del estado «providencia», se trata más bien de potenciar los recursos endógenos, de una «mise en valeur» del territorio y de la población montana que le permita acoger funciones económicas no marginadas.

\subsection{El modelo de desarrollo integrado}

Planteamos el establecimiento de un modelo de desarrollo que, como objetivo global, pasa necesariamente por promover el desarrollo y frenar la regresión demográfica, a cuyos efectos se plantean cuatro objetivos básicos:

- Romper el aislamiento de la comarca, sobre todo de sus zonas más deprimidas.

- Mejorar la calidad de vida de sus habitantes mediante actuaciones sobre las infraestructuras y los equipamientos y servicios sociales.

- Desarrollar los recursos económicos disponibles, en especial los relacionados con la agricultura y el turismo.

- Proteger el patrimonio natural y cultural, compatibilizándolo con el desarrollo económico.

Estos objetivos generales se traducen en una serie de objetivos particulares, tanto de carácter sectorial como territorial: 
La conservación de las masas forestales de la comarca es prioritaria, no sólo por los aspectos ecológico-paisajísticos, sino por sus efectos sobre la infiltración de agua en los acuíferos y la protección del suelo. Por ello se hace necesaria la restauración de las zonas afectadas por incendios así como la realización de tratamientos selvícolas que mejoren las condiciones fitosanitarias de los montes comarcales. Asimismo es imprescindible la reconstrucción y mantenimiento de los murales de las terrazas de cultivo (bancales) para reducir los riesgos de erosión y conservar el suelo.

La protección de la fauna no presenta problemas; es perfectamente compatible con los usos actuales del territorio. Sólo la fauna de medios acuáticos se encuentra afectada por el grado de contaminación de las aguas, de ahí que se haga aconsejable el tratamiento y mejora de calidad del agua de los cursos fluviales (sobre todo, la red del Serpis) y de los embalses (fundamentalmente, el de Beniarrés). La pesca, al igual que la caza, pueden significar una fuente de ingresos complementarios para la comarca si se acometen mejoras de estas condiciones medioambientales.

\section{MODELO DE DESARROLLO DE LA MONTANA}

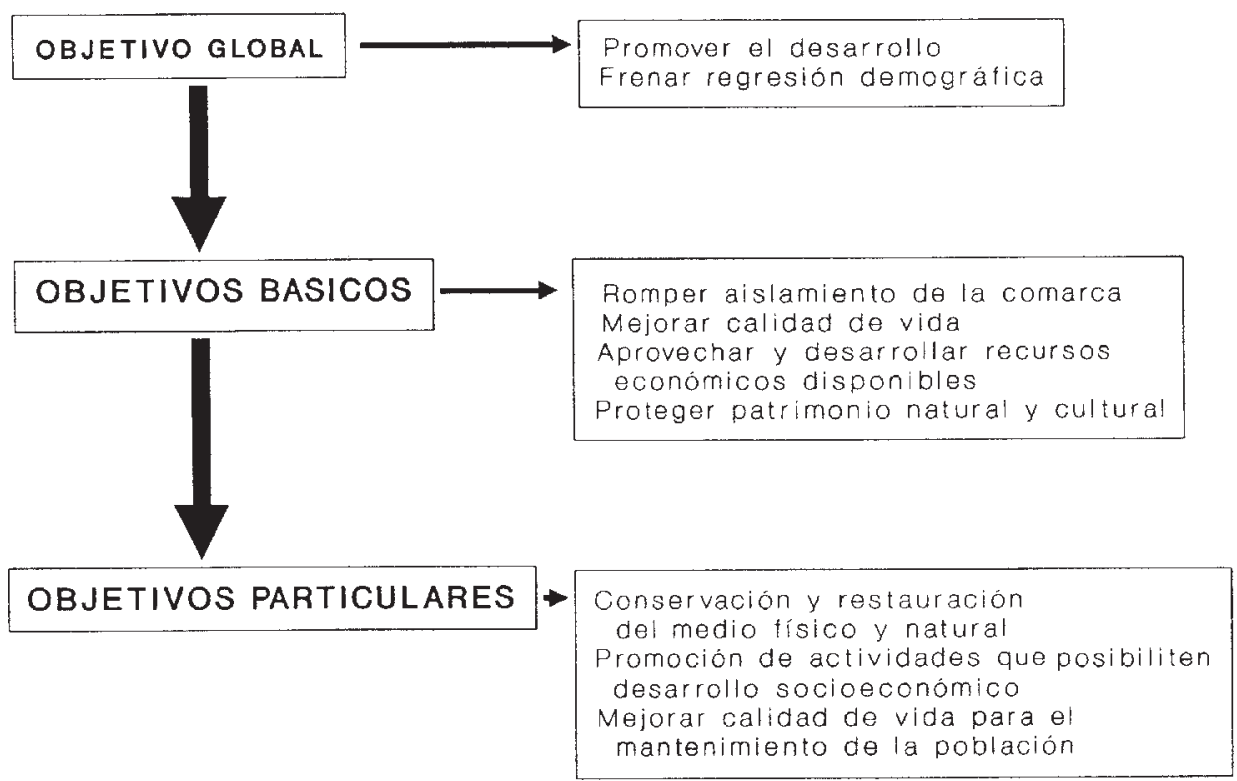


2.1.2. Promoción de actividades dirigidas a posibilitar el desarrollo económico y social

La actividad agrícola comarcal presenta limitadas posibilidades de desarrollo debido a una serie de condicionamientos: falta de motivación y envejecimiento de la población activa agraría, parcelas de pequeño tamaño, imposibilidad de ampliar la superficie regable. Por ello, este sector tiene una importancia relativa, tanto menor cuanto más próximos se encuentren los ejes industrial y turístico que flanquean la comarca.

El pequeño tamaño de las explotaciones y el excesivo número de parcelas que presentan podría solucionarse «en teoría» con la concentración parcelaria, pero las características de la zona imposibilitan cualquier actuación en ese sentido, que, como máximo, podría pasar por promover una política de compra-venta que racionalizara la distribución de la tierra, medida especialmente necesaria en municipios con alta dependencia agrícola y excesivo grado de parcelación.

Por otro lado, y bajo el asesoramiento de los servicios de Extensión Agraria, debería realizarse una reestructuración de los cultivos para mejorar la productividad y facilitar el mantenimiento de la actividad agraria. En este sentido, la desaparición del almendro — que va desapareciendo de las zonas marginales con riesgo de heladas - abre paso a otros cultivos; nogal, plátano, plantas aromáticas, etc. Estas últimas — aromáticas y medicinales - gozan de gran interés popular, aunque su cultivo sólo tiene interés si se realiza en cantidades importantes y se tiene control sobre la comercialización.

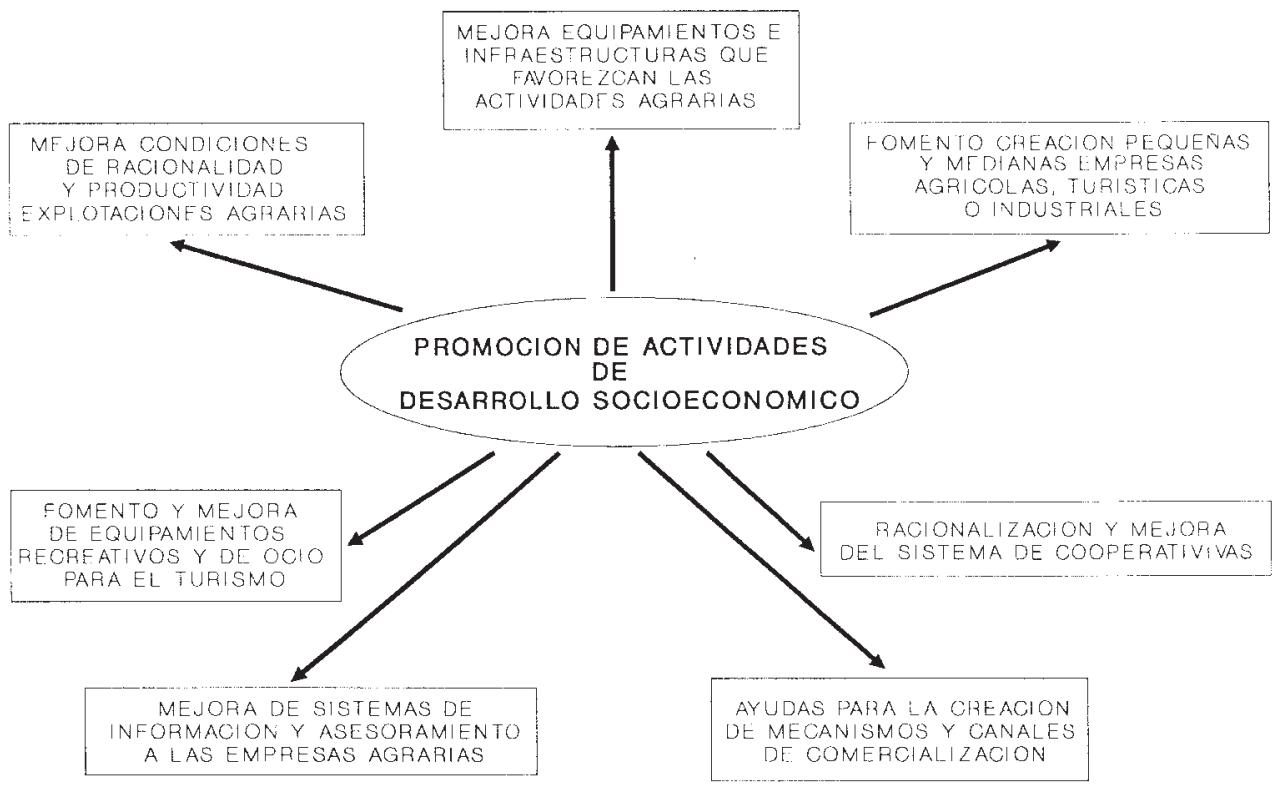


Con todo, los cultivos que han registrado mayor incremento en los últimos años han sido el melocotonero y el cerezo; sobre todo, en el caso de éste, a raíz de la creación de la cooperativa de cereza «La Montaña de Alicante», pese a que las dificultades de cultivo y los elevados costes han reducido su competitividad y frenado su expansión.

El olivo, perfectamente adaptado a las condiciones climáticas y edáficas de la zona, sigue siendo, junto con el almendro, el que más superficie ocupa en La Montaña, habiéndose favorecido su mantenimiento por las mejoras, en cuanto a producción de aceite y comercialización, introducidas por las cooperativas de Cocentaina y Muro.

En cuanto a equipamientos e infraestructuras para favorecer el desarrollo de la actividad agrícola, se han centrado en la realización de caminos rurales, que se han incrementado en la última década (tanto por actuaciones del IRYDA, como por las inversiones efectuadas por la Consellería de Agricultura, que en el último quinquenio han superado la cifra de 2.500 mill. de ptas.); de ahí que, salvo necesidades no cubiertas por algún municipio, se puede afirmar que la red de caminos rurales de La Montaña responde a las necesidades existentes, por lo que sólo se hace necesario actuar en su mantenimiento.

La infraestructura de riego se halla poco desarrollada en la zona, debido a la dificultad y elevado coste de realizar este tipo de mejoras a causa de la abrupta orografía que condiciona los abancalamientos aterrazados. Por otro lado, los recursos hídricos existentes, se limitan, según el IRYDA, a las aguas superficiales, cuya regulación sirve para abastecer las necesidades urbanas y agrícolas de la franja litoral; por ello, las actuaciones posibles, en este punto, se limitan a la adecuación y mantenimiento de las redes de acequias de la proximidades de los cursos fluviales (sobre todo, el Serpis), y la instalación de riego por goteo en zonas en que los desniveles lo permitan (proyecto de goteo para mejora de la cereza en Vall de Gallinera).

Finalmente, en relación con los procesos de comercialización de los productos agrarios, es necesario el cooperativismo. En este sentido, la comercialización del aceite de oliva, uno de los principales productos de la comarca, se realiza a través de las cooperativas de Muro (SOCAPMA), Cocentaina, Beniarrés y Gayanes, que ofrece distintas alternativas, asi como unas infraestructuras singularizadas. La comercialización de la producción frutícola se realiza, sobre todo, a través de la cooperativa «Cerezas de la Montaña de Alicante», que agrupa, como se ha indicado, a productos de Vall de Gallinera, Planes y Benimarfull.

La ganadería intensiva, centrada en el engorde de cerdos y pollos, muestra una cierta estabilidad, toda vez que su crecimiento depende de las posibilidades de comercialización por las empresas que controlan el sector. En cambio, la ganadería extensiva ofrece posibilidades de desarrollo en función de la disponibilidad de pastos, aunque este desarrollo tropieza con dos dificultades: en primer lugar, la 
saturación de mercado y falta de vías de comercialización que hacen que la rentabilidad sea escasa, y en segundo lugar, la falta de motivación de la juventud para dedicarse a esta actividad (que cuestiona a medio plazo su existencia). Por todo ello, es necesario fomentar su práctica entre la población activa joven y promover la creación de entidades asociativas de explotación compartida.

La actividad industrial, centrada en el eje Cocentaina-Alquería-Muro, hace que cualquier iniciativa industrial se dirija a estos municipios o a su entorno (Alcocer de Planes, Benimarfull). En cualquier caso, cabe citar la posibilidad de instalar industrias relacionadas con la agricultura o con los recursos naturales (plantas embotelladoras de agua mineral, envasadora de aceite de oliva, elaboración de embutidos, conservas de frutas, productos de destilería y envasado de plantas aromáticas y medicinales).

En cuanto al sector turístico, La Montaña dispone de importantes recursos paisajísticos, ecológicos, históricos y arquitectónicos que la hacen adecuada para un desarrollo de este sector que beneficie la población y asegure la conservación de estos recursos. Con todo, esta actividad ofrece dos posibilidades: el sector occidental puede actuar como zona de ocio y esparcimiento o incluso, zona residencial, para los habitantes de los núcleos industriales (Muro, Cocentaina, Alquería, Alcocer, etc.), mientras que el sector oriental se halla más específicamente orientado al turismo habitual de la costa alicantina. En este sentido, los municipios que más probabilidades tienen de actuar como zonas residenciales de los núcleos industriales son Benifallím, Benilloba, Gorga, Millena, Benillup, Benimarfull, Planes, Gayanes, Alcocer de Planes y Beniarrés. Por su parte, la mejora de la C3313, entre Callosa de Ensarria y Alcoy, ha supuesto una mejoría notable en los accesos a La Montaña desde Benidorm, que puede ser positivo para el turismo que accede por el Valle de Guadalest.

Por otro lado, aparte de la mejora de accesos, se hace aconsejable, para mejorar la demanda turística, realizar itinerarios (debidamente señalizados con información de tipo turístico y cultural), señalizar circuitos para senderismo y cicloturismo de montaña, informar sobre paisajes culturales, acondicionar zonas de acampada, aprovechar los embalses existentes (Beniarrés y Guadalest) para realizar actividades recreativas, restaurar y conservar el patrimonio histórico-cultural mediante la creación de Escuelas Taller y convenios con el INEM, ampliar la oferta de restaurantes y alojamientos, promover ayudas para la rehabilitación de casas en los pueblos, editar una guía turística de La Montaña que contemple rutas, sendas o itinerarios diversos.

Un aspecto de importancia para la ordenación de la actividad turística en la zona, en lo relativo al desarrollo urbanístico, es la necesidad de acometer el planeamiento urbanístico, bien a nivel municipal o a nivel comarcal mediante un Plan Director, para evitar los efectos negativos que una actividad urbanística desordenada puede provocar en la zona. 
2.1.3. Mejora de la calidad de vida para lograr el mantenimiento de la población

Aunque determinados servicios municipales (alumbrado público, red eléctrica, pavimentación, abastecimiento de agua potable, alcantarillado) se hallan en buenas condiciones en gran parte de municipios, - salvo pequeños problemas puntuales-, también es cierto que, en cambio, la depuración de aguas residuales y el tratamiento de residuos sólidos presentan ciertas deficiencias a nivel comarcal. Por ello, el logro de una mejor calidad de vida pasa por la realización y ejecución de un plan de saneamiento comarcal que incluya la instalación y mantenimiento de estaciones depuradoras de aguas residuales (sólo presentes, actualmente, en Cocentaina, Muro y Alquería), la integración de los municipios de La Montaña en los planes de resíduos sólidos y la adecuación de la red de abastecimiento de agua potable.

En otro orden de cosas, las ventajas que puede aportar a la comarca su proximidad a grandes núcleos industriales y turísticos depende de la viabilidad de los accesos, de ahí que el objetivo de un modelo de desarrollo víal contemple la mejora y adecuación de la red viaría, como forma positiva de contrarrestar el relativo aislamiento de la zona.

Finalmente, la restauración de las viviendas abandonadas puede ser de interés, por cuanto suponen un importante potencial para la oferta turística, al tiempo que contribuiría a mantener la estructura urbana tradicional; un régimen especial de ayudas podría servir para solucionar este objetivo.

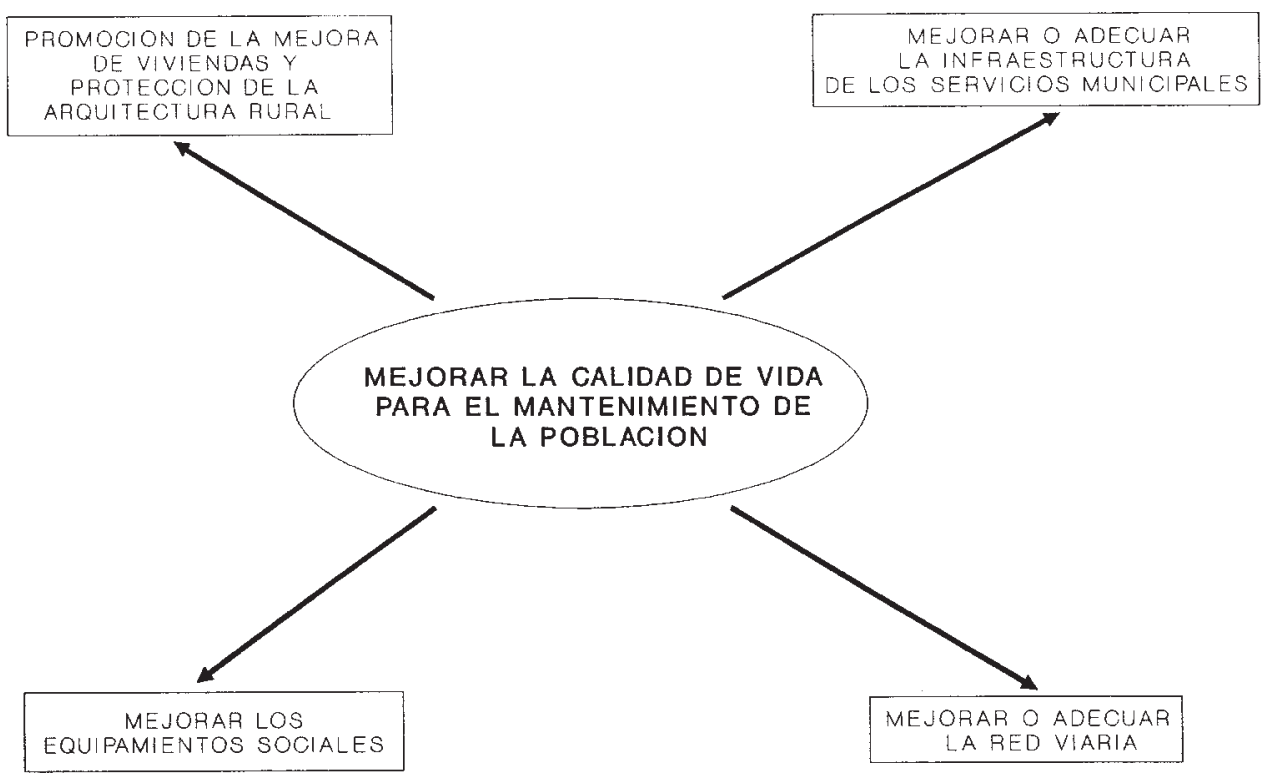




\section{Definición de las potencialidades turísticas de la montaña de Alicante}

Los problemas que hoy en dia afectan a la agricultura de la montaña alicantina, como se ha indicado, vienen a ser reflejo del panorama provincial: paulatina descapitalización del sector, poca atención a la calidad de los productos, regresión de la superficie cultivada, escasa operatividad del cooperativismo, estructuras agrarias anquilosadas, envejecimiento de la población agrícola, falta de créditos «blandos» y subvenciones para la modernización de las explotaciones, son algunas de las circunstancias que justifican el escaso interés por la agricultura y el abandono que se ha producido en los últimos años de las tierras abancaladas de La Montaña.

Una alternativa para aumentar la rentabilidad de estas áreas del interior montañoso alicantino pasa por el fomento del Turismo Rural, toda vez que la actividad turística actual queda muy por debajo del potencial que presenta este sector en la comarca.

En efecto, contrastando con una coyuntura económica negativa que pone de manifiesto un desequilibrio entre la población y los recursos económicos tradicionales, La Montaña presenta otros recursos susceptibles de explotación económica, recursos asociados a actividades de turismo y ocio, tales como atractivos de carácter ecológico (sierras de Aitana o Serrella, por ejemplo), histórico (pinturas rupestres prehistóricas, despoblados moriscos,...), cultural, y aquellos vinculados a una demanda activa o pasiva, de componente ecológico-natural en el medio rural (tendencia creciente en el mercado turístico).

Se presenta, pues, una oportunidad para el desarrollo del turismo rural, pero ésta ha de ser bien entendida. El turismo rural, por su necesaria «implantación artesanal», no puede ser la panacea que resuelva todos los problemas económicos de esta zona, más bien, se trataría de un desarrollo del turismo integrado con las restantes actividades económicas (un monocultivo en espacio rural resultaría impensable), con el medio ambiente, con el patrimonio cultural y con la población autóctona.

La estrategia de un desarrollo turístico en espacio rural coincide con los planteamientos de política regional y agraria comunitarios, los cuales pretenden que el desarrollo rural descanse en otras actividades diferentes de las agrarias, reduciendo superficies cultivables y mano de obra del sector agrícola, y potenciando la repoblación forestal, extensificación de los cultivos y sistemas de producción más respetuosos con el medio ambiente (CALS, 1990).

Aparte de los efectos benefactores que el turismo rural puede tener sobre los municipios rurales, el desarrollo de este tipo de turismo supondría una diversificación del producto turístico alicantino y una cualificación de sus posibilidades.

Ante estas expectativas de desarrollo y demanda entre diversos grupos del turismo rural en La Montaña, se hace necesaria una planificación de la que careció 
en buena parte el turismo litoral y en la que intervienen toda una serie de oportunidades y riesgos.

\subsection{Oportunidades}

En cuanto a las oportunidades que comportan estos tipos de turismo destacamos:

- Presencia de diversos recursos de potencial turístico cuya conservación podría garantizarse a través de la actividad turística.

- Tendencias de la demanda en favor de productos turísticos rurales y de contenido ecológico. La progresiva fragmentación de las vacaciones implica que al viaje principal se sumen otros viajes, generalmente de menor duración, en los que el espacio rural se muestra como un destino competitivo.

- Existencia de una demanda embrionaria. Junto a una demanda turística de retorno con elevado porcentaje de vínculos familiares (fines de semana para los emigrantes con domicilio más cercano y, sobre todo, en verano), existen flujos de excursionistas y campistas durante determinadas épocas del año coincidiendo con días festivos (Semana Santa, sobre todo).

PLANIFICACION:

TURISMO RURAL EN "LA MONTANA"

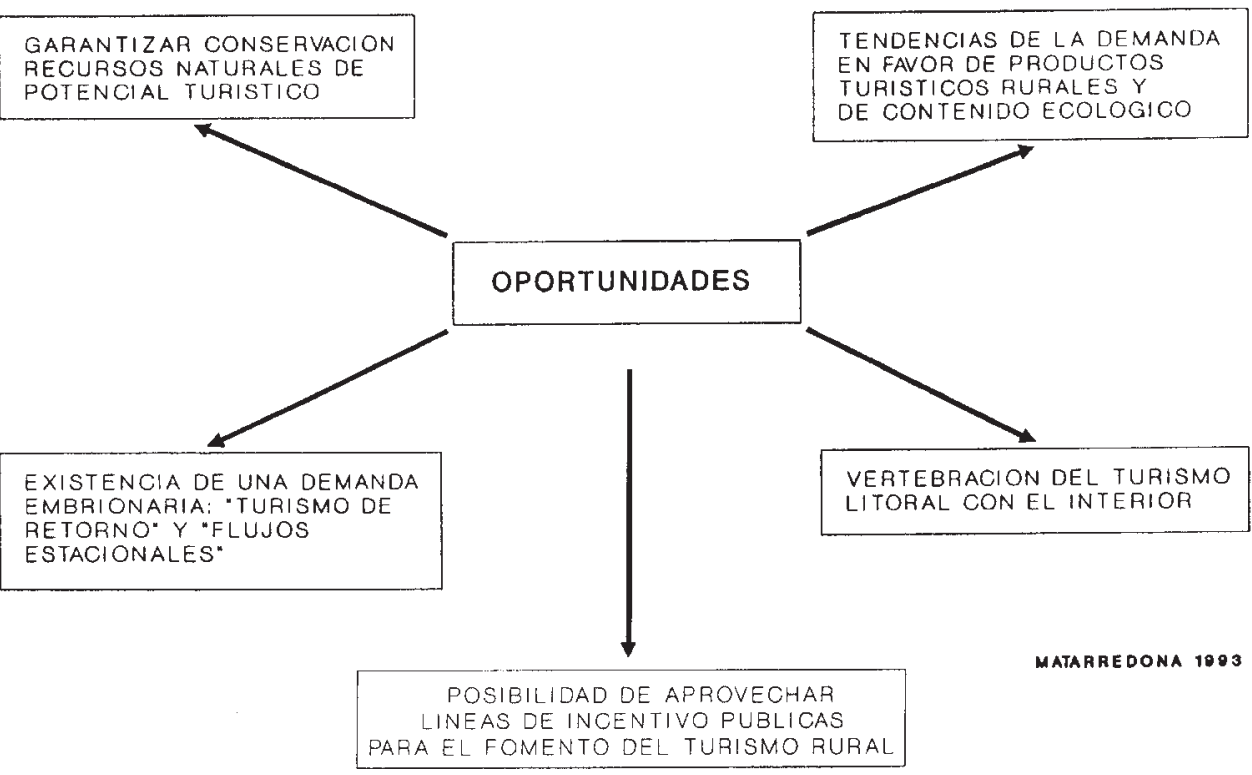


- Vertebración del turismo litoral con el interior. El desarrollo del turismo en La Montaña dependerá en gran parte de la demanda regional, hasta poder alcanzar el nivel de otros destinos rurales peninsulares con mayores ventajas comparativas (núcleos tradicionales de montaña mejor conocidos y más valorados por la demanda: Pirineos, Picos de Europa, etc.). La demanda regional es importante cuantitativamente al incorporar la población residente en la franja litoral, y toda la población turística flotante demandante de actividades de ocio.

- Posibilidad de aprovechar líneas de incentivo públicas para el fomento del turismo rural. La iniciativa comunitaria LEADER I ha tenido una notable repercusión en el crecimiento de la oferta turística de la zona, acumulando el capítulo de «Turismo» un montante económico muy superior al de otras líneas de actividad potencialmente cofinanciables. Igualmente, el «Programa de Turismo de Interior» auspiciado por la Administración autonómica está teniendo sus efectos a través de la creación de oferta de alojamiento con el fin de crear un «efecto demostración» (Camping de Vall d`Alcalá) y dinamizar iniciativas privadas, y de la creación de instrumentos de promoción (folletos turísticos). Es previsible que, tanto el programa autonómico como la iniciativa comunitaria LEADER II, continúen jugando un papel importante en la evolución del turismo en La Montaña alicantina, si bien resultan de obligada consideración las limitaciones que pueden derivarse de una actividad altamente subsidiada y la necesidad de una planificación rigurosa en la asignación y gestión de estas líneas de incentivo.

\subsection{Riesgos}

Y con referencia a los riesgos que tales planteamientos pueden generar, citamos:

- La incipiente demanda turística necesita una regulación que evite sus impactos negativos. La masificación de La Montaña durante determinadas épocas del año genera problemas para la población autóctona (escaso respeto por los espacios cultivados), polución de distintos tipos y, a veces, daños irreversibles (incendios).

- La interrelación de la demanda turística litoral con los espacios del interior se ve dificultada porque, de momento, el grueso de la demanda mantiene una motivación propia de «sol y playa». La superación de esta motivación exclusiva constituye un elemento clave para el turismo de interior, proceso creciente entre los estratos de la demanda de mayor formación y poder adquisitivo.

- Problemas de accesibilidad y déficit de servicios públicos inherentes a todo espacio rural, aunque con un buen grado de interacción con las áreas litorales (Denia, Jávea, Altea, Benidorm y Villajoyosa) y la de Alcoy-Cocentaina-Muro (dependiendo de cada municipio) que nos impide catalogar esta zona como de «rural profunda». 
- Posibilidad de seguir un crecimiento turístico espontáneo y especulativo en función de procesos urbanizadores. Las áreas de montaña alicantinas presentan baja densidad de urbanización por sus problemas de accesibilidad y porque los procesos de «rururbanización», propios de sociedades desarrolladas (doblemente significativos por servir a residentes fijos y a turistas), se han concentrado en el espacio litoral. La urbanización masiva de los espacios interiores de La Montaña supondría inhabilitarlos para el desarrollo de una actividad turística continuada. La creación de la oferta de alojamiento debe orientarse hacia la recuperación del patrimonio inmobiliario desocupado de los núcleos tradicionales.

- Definición de la escala de implantación turístico. En el medio rural el desarrollo del turismo ha de seguir necesariamente una «estrategia artesanal» (BOTE, 1988), puesto que «la generación de externalidades negativas (especialmente medioambientales) se presenta ya de forma sensible para pequeñas dimensiones de la actividad productiva» (CALATRAVA, 1988). La fragilidad de los ecosistemas de montaña comporta un desarrollo blando del turismo, ateniéndose a los límites ecológicos, económicos, sociales y culturales de cada área geográfica. Con todo, en consonancia con una implantación turística reducida y controlada no puede confiarse la solución a los problemas económicos de estas áreas, únicamente a los ingresos por turismo. Las rentas así generadas deben constituir un complemento de las rentas familiares procedentes de otras actividades.

\section{PLANIFICACION: \\ TURISMO RURAL EN "LA MONTANA"}

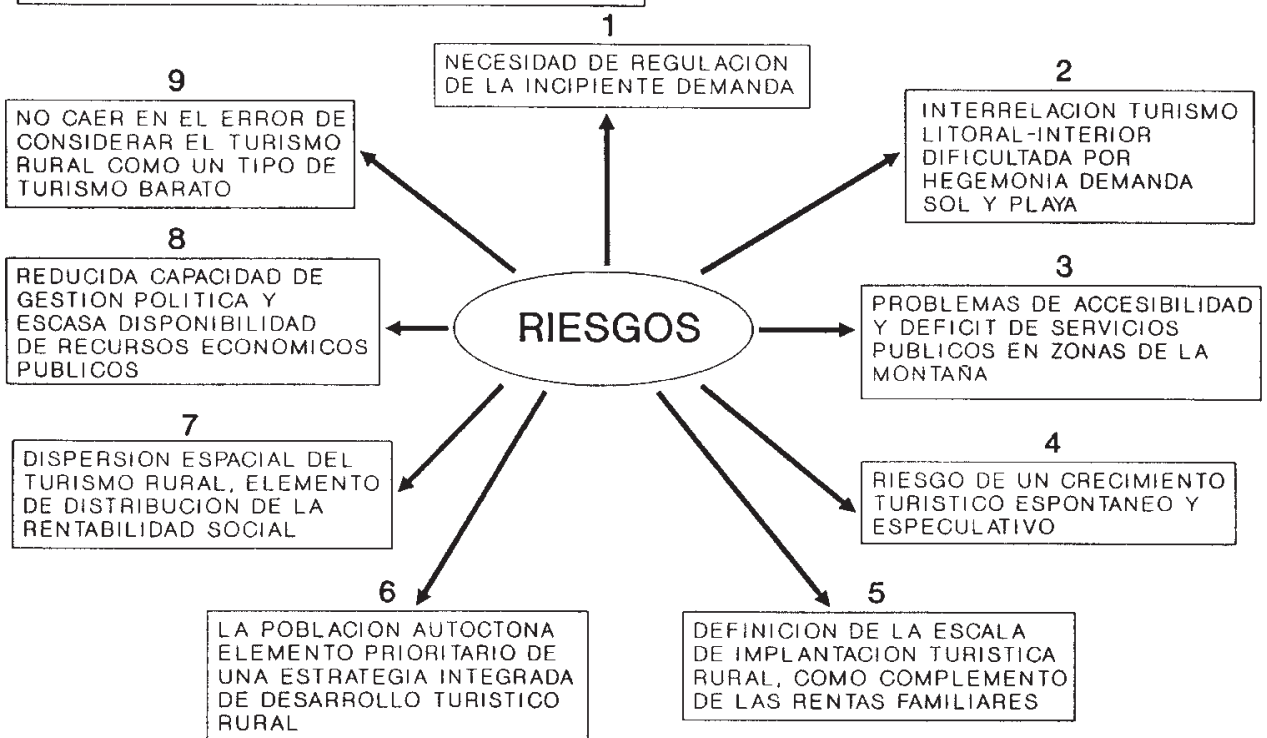


- La pluriactividad económica es una garantía contra cualquier tipo de monoespecialización productiva, sirviendo para paliar la estacionalidad de las actividades agrícolas y también turísticas. La progresiva implantación de un turismo rural, aunque artesanal, incrementará inevitablemente el porcentaje de población activa dedicado a esta actividad pero también dinamizará otros sectores productivos (productos agrícolas o ganaderos autóctonos para restauración, productos de fabricación artesanal, etc.). El turismo rural sólo puede entenderse en pequeña escala, de lo contrario, es otra cosa. Unicamente de este modo se puede configurar un producto atractivo para la demanda cuya explotación genere efectos positivos perdurables en el tiempo.

- Una estrategia integrada de desarrollo turístico rural ha de contar con la población autóctona como elemento prioritario tanto participando en la definición del modelo turístico como beneficiándose de su puesta en funcionamiento. No obstante, tal premisa presenta dificultades de aplicación en La Montaña debido a una estructura poblacional envejecida en la mayoría de los municipios, incluso en regresión demográfica, y una escasa formación e iniciativa empresarial. Para subsanar estos inconvenientes las tareas de dinamización y concienciación social ocupan un lugar importante y previo a actuaciones definitivas en materia de desarrollo turístico.

- Conviene una dispersión del turismo por todos los municipios de La Monta$\tilde{n} a$, desde el punto de vista de la rentabilidad social, de acuerdo con sus potencialidades, más que un desarrollo concentrado en pocos y exclusivos municipios; por otra parte, algunas actividades de ocio en espacio rural requieren una dispersión de los alojamientos, tal es el caso de los albergues de etapas franceses que sirven a senderistas y cicloturistas.

- La Montaña presenta una reducida capacidad de gestión política y escasa disponibilidad de recursos económicos públicos derivados de un escaso potencial demográfico y de su estructura poblacional. El asociacionismo municipal puede contribuir a superar estos inconvenientes y ser una plataforma para la planificación y la gestión turística. El precedente más inmediato y esperanzador en La Montaña es la Mancomunitat del Xarpolar, integrada por Planes, Vall de Alcalá y Vall de Ebo, entre cuyos fines figura «el desarrollo económico, sociocultural y turístico de los pueblos implicados» (orden de 24 de noviembre de 1992 de la Consellería de Administración Pública).

- La creación de una oferta turística básica no puede caer en el error de considerar el turismo rural como un tipo de turismo barato (experiencias nacionales e internacionales demuestran la incongruencia de tal planteamiento). El tipo de oferta que se cree, condicionará el posicionamiento del producto turístico rural y lo orientará hacia unos segmentos de la demanda u otros. Debe incentivarse la creación de una oferta con atractivo en sí misma. Conviene huir por ejemplo, en el caso del alojamiento, de una oferta convencional y fomentar productos personalizados a 
través de las propias instalaciones y de los servicios y del trato personal. De acuerdo con este planteamiento, la rehabilitación de establecimientos termales (Benimarfull, por ejemplo) y establecimientos de valor histórico o cultural presentan muy buenas expectativas en el mercado turístico (aunque estas operaciones deben ir acompañadas de concienzudos estudios de viabilidad).

Como respuesta a esta incipiente dinámica, se ha podido observar en los últimos años un cierto interés en impulsar este sector a través de: la,...)

- Construcción de unifamiliares y chalets adosados (Torremanzanas, Penágui-

- Proyectos de construcción de campo de golf (Benilloba, Gorga, Penáguila, Torremanzanas, la Hedrera...)

- Rehabilitación por parte de los Ayuntamientos de algunos lugares o edificios de interés turístico (Jardín de Santos, en Penáguila;...)

- Interés en la adquisición de terrenos para urbanizar y campings (Vall de Seta, alrededores del pantano de Beniarrés). En este punto es significativo que al anunciarse la construcción de depuradoras en el Valle del Serpis se detectara un incremento de compras de terrenos en los alrededores del pantano de Beniarrés, pensando en su reconversión para la práctica de deportes naúticos.

- Posibilidad de surgimiento de urbanizaciones y campings en Alcocer de Planes, Gayanes, Lorcha, Beniarrés, siempre que se superen los problemas relativos a las infraestructuras básicas (abastecimiento de agua, recogida de basuras, alumbrado, calificación de terrenos, etc.)

- Acondicionamiento de zonas de acampada o campings en Almudaina, Vall de Gallinera, Vall de Ebo, Benimantell y Vall de Alcalá.

— Incremento en la adquisición de «casas de pueblo», tendencia observada en Tárbena, Bolulla y Valle de Guadalest, y, en menor medida, en Beniarrés, Gayanes, Alcocer, Agres y Penáguila.

En definitiva, parece que el turismo constituye una fuente de actividad y riqueza, única alternativa para que la población joven permanezca en la zona, si bien es cierto que el desarrollo del sector tropieza con una serie de inconvenientes: deficiente estado de la red viaria, falta de una adecuada ordenación y promoción de la oferta turística y escasez de equipamiento e instalaciones de ocio y recreo (PÉREZ ESPARCIA-ESTRELA NAVARRO, 1991).

En conclusión, la vertebración funcional del turismo de montaña con el litoral es una cuestión básica. Efectivamente, dentro de las posibles vías de cualificación y diversificación del producto «sol y playa», la oportunidad de ofrecer un espacio natural diferenciado con valores ecológicos, históricos y culturales a una demanda cada vez exigente y ante la existencia de destinos competidores que no tienen esta posibilidad de diversificar su producto turístico, ocupa un lugar importante. Sin embargo, La Montaña no puede ser «la zona verde» de un litoral en extremo urbanizado donde se localicen los consumos turísticos principales (en función de 
su gran potencial de oferta básica y complementaria), relegando el interior a excursiones o visitas esporádicas con impactos notorios y baja generación de rentas.

Se trata de configurar dos productos turísticos diferentes, pero que pueden complementarse entre sí a causa de un elemento distintivo como es su proximidad (se puede hablar, incluso, de viajes combinados litoral-interior).

Ambos productos turísticos, individualmente considerados, pueden encontrar en la complementariedad del otro, un factor de competitividad importante y lograr un posicionamiento más favorable en el mercado turístico:

- Existen zonas con mayores recursos turísticos rurales que La Montaña, pero no todas disfrutan de una ubicación estratégica que permita añadir a las motivaciones propias del turismo en espacio rural la opción a disfrutar de la oferta turística y de ocio del litoral alicantino.

- Para el turismo de «sol y playa» predominante, la existencia de un traspaís con atractivo turístico no constituye, de ningún modo, un producto sustitutivo, sino la posibilidad de incrementar sus factores de atracción, de cualificar su imagen exterior y de satisfacer a los segmentos de la demanda cuyas motivaciones van más allá de la oferta tradicional de «sol y playa».

\section{Bibliografía}

AA.VV.: «Consideraciones sobre el turismo rural en España y medidas de desarrollo», Estudios turísticos, 108, 1990.

ABREU Y PIDAL, J.M. de: «Condicionantes para la delimitación y gestión de áreas de montaña españolas», Supervivencia de la Montaña, Ministerio de Agricultura, Madrid, 1981.

ASAMBLEA ECONÓMICA CONSULTIVA Y SOCIAL: Una política para las zonas de montaña, Comité Económico y Social de la CEE, Bruselas, 1988, 138 págs.

BARDÓN FERNÁNDEZ, Elena: «El turismo rural en España. Algunas iniciativas públicas», Estudios turísticos, Madrid, nº 94, 1987.

BOTE GÓMEZ, V.: «La estrategia del turismo rural integrado en España», Supervivencia de la Montaña. Actas del Coloquio Hispano-Francés sobre las Áreas de Montaña, Ministerio de Agricultura, Madrid, 1981, págs. 607-614.

BOTE GÓMEZ, V.: Turismo en espacio rural. Rehabilitación del patrimonio sociocultural y de la economía local. Edit. Popular S.A., 1988.

CABERO DIÉGUEZ, V.: «Estado actual de las regiones montañosas», La Región y la Geografía Española, Valladolid, 1980, págs. 243-258.

CALATRAVA, S.: «Análisis de la importancia del turismo rural como elemento generador de rentas complementarias en zonas de depresión socioeconómica: el caso de las Alpujarras», Coloquio Hispano-Francés. Áreas Rurales. Casa Velázquez, Madrid, 1988.

CALS, S.: «Reflexiones de un economista sobre la utilización turística y social de los espacio naturales protegidos», MAPA, Madrid, 1990. 
CARITAS ESPAÑOLA: Guía de recursos comunitarios en el mundo rural. Madrid, 1987, Editorial Popular, S.A.

CRUZ OROZCO, J.: «Las áreas montanas valencianas: crisis y reactivación», Cuadernos de Geografía, 44, Valencia, 1988, págs. 183-202.

CRUZ OROZCO, J.: Les comarques de muntanya, I.V.E.I., Valencia, 1990, 158 págs.

CRUZ OROZCO, J.: «Changements recents dans les zones montagneuses du Pays valencien», Revue Geographique des Pyrenees et du Sud-Ouest, 61-2, 1990, págs. 187-203. FERNÁNDEZ DEL MORAL, J.M.: «La ley de Agricultura de Montaña y las vias comunitarias sobre la materia», CISS. Noticias/CEE, 73, 1991, págs. 21-26.

FRUTOS GARCÍA, J.: «Conservación y degradación de recursos autóctonos», Curso sobre Desarrollo Integrado en Áreas Desfavorecidas, CSIC-Fundación Banco Exterior, Madrid, 1985.

GARCÍA ÁLVAREZ, A.: «Delimitación de la montaña y criterios para su ordenación», Supervivencia de la montaña, Ministerio de Agricultura, Madrid, 1981, págs. 653-660.

GARCÍA FERNÁNDEZ, J.: «Sobre la montaña como hecho geográfico», Agricultura y Sociedad, Suplemento 2, Madrid, 1991.

GILBERT, D.: «Perspectivas del desarrollo del turismo rural» en Revista Valenciana d'Estudis Autonómics, Valencia, nº 13, 1992.

GÓMEZ OREA, D.: «El turismo rural. Alternativa de desarrollo en las comarcas desfavorecidas de montaña», Revista Urbanismo, COAM, págs. 41-51.

GROLLEAU, Henri: «España y la experiencia europea». Estudios Turísticos, no 110.

JARA IZQUIERDO, A.: «Ordenación integral de comarcas de montaña», Coloquio HispanoFrancés sobre Espacios Rurales, Ministerio de Agricultura, Madrid, 1983, págs. 377-386. MARCHENA, M.: «Un análisis de los recursos turísticos andaluces», en Revista de Estudios Regionales. Málaga, 1985-86, Vol. I.

OCDE: Nuevas tendencias en política rural. Madrid, 1990, MOPU-ITUR. (1ª edición de 1988)

ORTEGA VALCARCEL, J.: «La economía de montaña. Una economía de equilibrio». Eria-Revista de Geografía, 19-20, 1989, págs. 115-128.

PÉREZ ESPARCIA, J.: «Las zonas de montaña y áreas desfavorecidas», La Comunitat Valenciana en l'Europa unida. Projecte 93, Presidencia de la Generalitat Valenciana, 1990, 48 págs.

PÉREZ ESPARCIA, J. y ESTRELA NAVARRO, M.J.: «A propósito del Programa de ordenación y promoción de agricultura de montaña» del Alto Mijares y Alto Palancia (Castellón)», Cuadernos de Geografía, 49, 69-88, Valencia, 1991.

Programa de Ordenación y Promoción de Agricultura de Montaña de la Z.A.M. «La Montaña» de Alicante, Generalitat Valenciana, Consellería d’Agricultura i Pesca, 1991, 4 tomos.

Seminario Internacional sobre Turismo Rural: «España y la Experiencia Europea», 1991. VERA REBOLLO, F.: «La dimensión ambiental de la planificación turística: una nueva cultura para el consumo turístico» en Papers de Turisme, $\mathrm{n}^{\circ}$ 10, Institut turístic Valenciá, 1992.

ZEROLO AGUILAR, M.: «En torno al turismo verde y a sus entornos», Ecoturismo. Criterios de desarrollo y casos de manejo. Madrid, ICONA, Ministerio de Agricultura, Pesca y Alimentación (1992). 